\title{
Comparative Effects of Guided and Unguided Multiple Choice Objective Questions Tests on Students' Mathematics Academic Achievement According to Gender
}

\author{
Patrick Chukwuemeka Igbojinwaekwu, PhD \\ Department of Teacher Education, Faculty of Education, Niger Delta University \\ Wilberforce Island, Bayelsa State, Nigeria; parimeka@gmail.com
}

Doi:10.5901/jesr.2016.v6n2p193

\begin{abstract}
Students' low or poor academic achievement in mathematics at all levels in Nigerian educational system is very worrisome. This study, therefore, investigated, using pretest-posttest quasi-experimental research design, the extent which Guided and Unguided Multiple Choice Objective Questions Tests (GMCOQT and UMCOQT) improved the academic achievement of students in Senior School Mathematics in Delta State Capital Territory, Nigeria. The sample comprised 640 Students from four co-education secondary schools, randomly assigned to control and experimental groups. Four research questions and four null hypotheses guided this study. Three instruments, Comparative Achievement Test (CAT) 1, 2, and 3 were used to collect data. Difference in Mean Academic Achievement was subjected to z-test statistic and was significant in favor of the experimental group. Implications and recommendations for future research were advanced.
\end{abstract}

Keywords: Mathematics; Guided and Unguided Multiple Choice Objective Questions Tests; Students' Academic Achievement; Student's Gender.

\section{Mathematics and Its Importance in Nigerian Schools and the Society}

Mathematics is the science of structure, order, numbers, space and quantity; it is a relationship which revolves around the elementary practice of counting, measuring and describing of shapes and objects (Soyemi, 2002). Maduabum and Odili (2006) described Mathematics as the science of quantity and space which occupies a key position in the Nigerian Educational System. Graham in Igbojinwaekwu (2004) posited that mathematics is a general science in which arithmetic, geometry, algebra, trigonometry, etc are branches. Sowunmi in Igbojinwaekwu (2004) asserted that mathematics is the symbolic logic of possible relations and concerned with hypothetical truth. According to Igbojinwaekwu (2009), mathematics is a truthful way of finding solutions to problems; these problems abound in our everyday life activities.

In Nigeria, one of the ways through which any school, be it at the primary or secondary or tertiary level is assessed, is on the importance and attention given to the teaching and learning of mathematics (Igbojinwaekwu, 2013). This is because of the key position mathematics occupies in the Nigerian Educational System and its application in developmental processes of any nation. In this vein, Akuezuilo and Chinwoeke (2009) stated that mathematics is the bedrock of all science subjects and is, therefore, needed for scientific and technological advancement of any nation. Maduabum and Odili (2006) posited that mathematics occupies a key position in the Nigerian Educational System because of the vital role it plays in the advancement of science and technology in contemporary society. According to Mushau and Tijani (2011) and Mafiane (2006), any society which aspires to be scientifically and technologically developed must be ready to take mathematics education very serious, since mathematics has ingredients for the effective articulation of the abstract elements of science that gives impetus to the development of technologies. Ukeje in Okigbo and Okeke (2011) stated that without mathematics, there is no science, without science, there is no modern technology and without modern technology, there is no society. Ukeje (1997), therefore, concluded that mathematics is the precursor and the queen of science and technology and the indispensable single element in modern societal development. Abiodun in Chinweoke (2008) observed that while science is the bedrock that provides spring board for technology, mathematics is the gate and key to science; he concluded that any nation seeking scientific and technological development, must also address the issue of mathematics. Roger in Igbojinwaekwu (2013), explained that Mathematics has become the central intellectual discipline of the technological society and that as the society develops so will its quantitative aspects assume greater influence and dominance over its qualitative features. Eguavon (2002), described mathematics as the pivot of all civilization and technological development. Supporting Eguavon (2002), Imoko and Agwagah (2006), opined that mathematics is a key factor in the development of any nation. 
Mathematical concepts and symbols are used in expressing the physical laws of nature (Tsue and Anyor, 2006). Therefore, mathematical concepts and methods provide scientists with insight, into and about natural phenomenon. Njoku (2007), opined that chemical kinetics, chemical equilibrium, stiochemistry, mole concept, solubility, electrolysis, redox reactions and ionic equations are areas in chemistry that require a good knowledge of mathematical concepts. Maduabum and Odili (2006) identified ratio, charts, proportions, measurement and statistics as the mathematical concepts needed in biology. Tsue and Anyor (2006) indicated that algebra, trigonometry, graphs, calculus and differential equations are the mathematical concepts required in physics and engineering science. Realizing the views of the aforementioned researchers on the importance of mathematics in national development and its position in the school system, the Federal Republic of Nigeria (FRN) (2013) is continuously emphasizing the importance of mathematics in national development by making the subject compulsory for both pupils and students in Primary and Secondary Schools. Supporting FRN, Maduabum and Odili (2006), asserted that for a nation such as ours, aspiring for scientific and technological take-off, the need to pay due attention to our students academic performance in mathematics cannot be over emphasized.

Regrettably, despite the importance of mathematics as a key subject in realizing any nation's scientific and technological aspirations, there is ample evidence of continued low interest in the subject by Nigerian students (Okigbo and Okeke, 2011). Also, reporting to the National Council on Education (NCE) on students' performance in the May/June SSCE, the West African Examinations Council (WAEC, 2012, 2013 and 2014) lamented the low achievement and interest in mathematics by Nigerian candidates.

Many reasons have been advanced for the continuous dismal state of mathematics in Nigeria, at all levels of education. While some researchers (Ali, 2010; Harbor-Peters, 2001) viewed teachers' incompetence as a contributing factor, other findings (Akuezuilo and Chinweoke, 2009; Okigbo and Okeke, 2011) attributed the low interest in mathematics to teachers' non utilization of appropriate teaching techniques. Many teachers in schools use only techniques (e.g. lecture and questioning) they know, even if such techniques are not relevant to the concept under discussion (Akinsola and Popoola, 2004). Opara (2004) advised that teachers should evolve strategies that involve learner's active participation. Such strategies will generate interest in the students. Igbojinwaekwu and Nneji (2012) attributed the high failure rate of students in Senior School Certificate Examination due to the structure of questions in the examination. No study, to the best of the knowledge of the researcher, has reported on the Comparative Effects of Guided and Unguided Multiple Choice Objective Questions Tests on Academic Achievement of Students in DSCT, Nigeria. This was what aroused the researcher's interest.

\section{Academic Achievement of Students}

Academic achievement is the score or grade a student obtains after sitting for an examination or a test. It could be an internal or external examination; formal or informal. During teaching-learning process, the teacher has his behavioural objectives which the students will attain by the end of the lesson. The teacher, also, has some evaluative questions, each assessing one behavioural objective. Simply put, if there are three behavioural objectives, there must be three evaluative questions to ascertain the extent of attainment to the behavioural objectives. Therefore, academic achievement of students is assessed base on the extent of attainment to the behavioural objectives, by the end of a given lesson.

According to Jona-Eteli (1999), the assessment tests commonly use, by the teachers, in Nigerian schools are diagnostic, formative and summative. Egbule (2002) affirms that diagnostic assessment occurs at the early part of the lesson. It takes the form of pretest or entry behaviour of the students. This enables the teachers to know where and how to start a lesson. Ndu, Okeke and Igbojinwaekwu (2005) assert that formative assessment includes assessment at the end of a lesson, a quiz, any test which is marked and the scripts are returned to the students, learning-oriented practical tests and mock examinations. Jona-Eteli (1999) opines that summative assessment is the examination given to students to mark the end of a given programme or course. It is, mostly, used by examining bodies in external examinations. Supporting Jona-Eteli (1999), Ndu, Okeke and Igbojinwaekwu (2005) confirm that summative assessment is one whose aim is to grade or certify the students. Example of summative assessment is final course examinations; General Certificate in Education (G.C.E.), West African Senior School Certificate Examination (W.A.S.S.C.E.), etc.

\section{Student's Gender}

The student's gender is based on whether the student is a male or female. In Nigeria, there are certain things expected of a male child, as well as the female child. The male child is the parental focal point, because he is to inherit his father's 
property and takes his roles when the father dies. The female child is regarded as weaker and less intelligent than the male child. Above all, the female child will, eventually, be married into another family. A female child who is very successful in science, mathematics and technology is regarded as not good enough for marriage (United Nations Educational, Scientific and Cultural Organization (UNESCO), 2000). So, the female child is not expected to be more or of equal intelligence with her male child counterpart (Igbojinwaekwu, 2002).

\section{Guided and Unguided Multiple Choice Objective Questions Tests}

It is a common knowledge that teachers are the implementers of the curriculum. It is through teaching of various subjects, by the teachers, that the task of curriculum implementation is done. This actually occurs during the teachinglearning process. The teacher actually has a set of behavioral objectives which the students have to attain by the end of the lesson. So, by the end of the lesson, the teacher evaluates the students through some questions or tests to know the extent of attainment of the behavioral objectives.

One of the tests used by the teachers to evaluate the level of attainment of the behavioral objectives by the students is the Objective Questions Test. According to Egbule (2002), objectives test is a well structured test item in which the examinee or student is required to identify or select the correct option from a given set of alternatives. He added that there are several types of objective questions which include: (i) multiple choice, (ii) true or false / yes or no, (iii) matching items and (iv) fill in the blank space. This paper delimits itself to the Multiple Choice Objective Questions Test. According to Jonah-Eteli (1999), Multiple Choice Objective Test is a question with three or more alternatives out of which one is correct; the more the alternatives the more reliable to a point. He emphasized that the choice of the number of alternatives depends on the age and ability level of the examinees. They could be designed to assess objectives at any level of the domain.

In some subjects, the objective test is guided, while in other subjects, it is unguided. An example of the subject where there is guided objective question is English Language. In this case, an example is given to the students to guide them answer a set of objective tests. In a subject like Mathematics, most questions are presented to the students without guided examples. The objective questions test that is guided with example is called Guided Multiple Choice Objective Questions Test, while the one without guided examples is called Unguided Multiple Choice Objective Questions Test.

According to Igbojinwaekwu (2012), the Guided Multiple Choice Objective Questions Test directs the examinees to the correct option easily, than the Unguided Multiple Choice Objective Questions Test. He stated that Guided Multiple Choice Objective Questions Test gives the students an advantage to recall easily than the unguided questions. Also, the difficulty experienced by students to memorize facts is removed by the Guided Multiple Choice Objective Questions Test, while the Unguided Multiple Choice Objective Questions Test encourages memorization of facts. The Guided Multiple Choice Objective Questions Test encourages application of knowledge rather than memorization.

Guided Multiple Choice Objective Questions Test emanated from Guided Discovery Method of Teaching in which the learner is presented with problems and at the same time given a number of cues, hints and instructions that could guide him/her solve the problems (Oghenevwede, 2012). In other words, this method is student or learner centered and, so, gives the student the independence of using the cues, hints and instructions to arrive at the needed answers to the given problems. This agrees with FRN (2013) which de-emphasized memorization and regurgitation of facts which are common in schools, today, but emphasized practical exploratory and experimental methods of teaching, which should be accompanied with guided method of assessment and which can lead to a sustainable high academic achievement of students and development of the nation, at large.

In this era of loaded curricula, students' discouraged results in Mathematics, year after year in SSCE, concerned mathematics teachers and other stakeholders in education are looking for a strategy to make students perform better in Mathematics. Akpan (1987) has recommended in one of his researches that teachers should find ways to encourage both boys and girls to study and pass Mathematics with ease at all levels. This appeal, also, gave birth to this study.

\section{Statement of Problem}

Examination/test is one of the important ways of evaluating the curriculum implemented. Also, the type of examination/test that is given to students in course of teaching-learning process, is equally important, because apart from assessing whether the behavioral objectives of the topic are attained, it is used to find out if the teacher has to change his teaching method or not. Igbojinwaekwu (2012) affirms that in Senior School Certificate Examination (SSCE) Oral English Paper, Guided Objective Questions are used to test the performance of Senior School Students and that 
students' performance are found to be better than those tested with Unguided Objective Tests. The researcher, therefore, wanted to know if the same situation could be applicable to mathematics students at the senior school level. The statement of the problem is, therefore, stated thus: what are the Comparative Effects of Guided and Unguided Multiple Choice Objective Questions Tests on Academic Achievement of Students in Mathematics, By Gender, at the Senior School Level?

\section{Research Questions}

The following four research questions guided this study.

1. To what extent has Guided Multiple Choice Objective Questions Test improved the Mean Academic Achievement Scores (MAAS) of Senior School 2 (SS2) students in Senior School Mathematics?

2. To what extent has Guided Multiple Choice Objective Questions Test improved the Mean Academic Achievement Scores of SS2 Female students in Senior School Mathematics?

3. To what extent has Guided Multiple Choice Objective Questions Test improved the Mean Academic Achievement Scores of SS2 Male students in Senior School Mathematics?

4. How has Guided Multiple Choice Objective Questions Test improved the Mean Academic Achievement Scores of SS2 Female student's vis-à-vis their SS2 Male counterparts in Senior School Mathematics?

\section{Null Hypotheses}

The following four null hypotheses were tested at $\mathrm{P}<0.05$ level of significance on a 2- tailed test.

$\mathrm{HO}_{1}$ : There is no significant difference between the Mean Academic Achievement Scores SS2 students exposed

to Guided and Unguided Multiple Choice Objective Questions Tests in Senior School Mathematics.

$\mathrm{HO}_{2}$ : There is no significant difference between the Mean Academic Achievement Scores of SS2 Female students exposed to Guided and Unguided Multiple Choice Objective Questions Tests in Senior School Mathematics.

$\mathrm{HO}_{3}$ : There is no significant difference between the Mean Academic Achievement Scores of SS 2 Male students exposed to Guided and Unguided Multiple Choice Objective Questions Tests in Senior School Mathematics.

$\mathrm{HO}_{4}$ : There is no significant difference in Mean Academic Achievement Scores between SS2 Female and Male students exposed to Guided Multiple Choice Objective Questions Tests in Senior School Mathematics.

\section{Methodology}

The design employed in this study was the pretest-posttest quasi- experimental. This was because the researcher could not randomly sample and assign his subjects. Therefore, the subjects were used as groups already in existence as intact classes. In addition, intact classes, instead of subjects, were randomly assigned to experimental and control groups, due to the rigid administrative setup of the schools used in this study.

The population of the study was 2,240 (1,229 boys and 1,011 girls) Senior School Two (SS2) students from twelve public secondary schools in Delta State Capital Territory, Nigeria. These schools have been presenting students for Senior School Certificate Examination (SSCE) conducted by West African Examinations Council (WAEC) and National Examinations Council (NECO) for the past five years and beyond. All the twelve secondary schools were co-educational.

Through a simple random sampling technique, four schools were selected on paper, for this study. These four schools had 640 students (351 boys and 289 girls) in SS2.The SS2 students from two schools formed the control group, while SS2 students from another two schools formed the experimental group. The control group comprised 340 (227 boys and 113 girls) SS2 students. The experimental group consisted of 300 (124 boys and 176 girls) SS2 students.

Three instruments, Comparative Achievement Test (CAT) 1, 2 and 3 were used to collect data. The three instruments were researcher made. Each of these instruments consisted of two parts, A and B. Part A demanded for the personal data of each student, while B comprised 20 multiple choice objective questions on concept of polygon. CAT 1, 2 and 3 were similar except that the serial numbers of the questions were not the same and that all the multiple choice objective questions in CAT 3 were guided. Two experts, in mathematics education and another two experts in test construction validated the instruments, CAT 1, CAT 2 and CAT 3, on the bases of coverage of unit of work, relevance in collection of needed data and stated behavioral objectives. Kunder-Richardson 21 (K-R 21) statistic was used to determine the reliability indices of CAT 1, CAT 2 and CAT 3, which were 0.92, 0.92 and 0.91, respectively. K-R 21 statistic was used because CAT 1, CAT 2 and CAT 3 were dichotomous in nature. That is, the instruments required right 
or wrong answers from the respondents. These reliability indices were judged to be good enough to collect data for this study, following Maduabum (2004) and Egbule and Okobiah (2006) assertions that instrument made to collect data for academic achievement should have a reliability index of not less than 0.50 .

Four teachers, each from the four selected secondary schools in this study, taught the students. The teachers underwent training programme for two weeks, before they were certified, good enough, to teach the students. This was done, in order, to remove any inequality among the teachers. Uniform lesson notes, on the concept of polygon, were prepared for the teachers by the researcher. This was to ensure that the four teachers teach exactly the same thing using the same steps, method, behavioral objectives and study questions or evaluative questions. The four teachers used in this study had the same years of experience in terms of service years, West African Examinations Council (WAEC) examiners in SSCE and were all degree (B.Sc.Ed) holders in Mathematics. This was to avoid the effects of intervening variables like year of teaching experience, external examiners experience and differences in degree from the participating teachers. In addition, the same text book was used by the teachers during teaching-learning process. This was to avoid the effect of extraneous variable, like differences in text books, on the validity of the results in this study.

The students from the two groups, control and experimental, were subjected to pretest, using CAT 1 as a test instrument for 30 minutes, before the commencement of teaching-learning process. Thereafter, the students in both control and experimental groups were taught for three weeks, after which students in the control group were post-tested using CAT 2 (UMCOQT) and the students in experimental group were post-tested using CAT 3 (GMCOQT) as test instruments, for 30 minutes, respectively. Data collected from CAT 1, CAT 2 and CAT 3 were subjected to analyses using percentages and z-test statistic. The z-test statistical tool was used to analyze data because the sample was large $(\geq 30)$.

\section{Data Analysis and Results / Findings}

\subsection{Research Question 1}

To what extent has Guided Multiple Choice Objective Questions Test improved the academic achievement of SS2 students in Senior School Mathematics?

\subsection{Answer to Research Question 1}

The extent to which Guided Multiple Choice Objective Questions Test improved academic achievement of SS2 Students in Senior School Mathematics is shown in table

Table 1: Pretest-Posttest Mean Academic Achievement Scores (MAAS) of SS2 Students in Senior School Mathematics

\begin{tabular}{|l|c|c|c|c|}
\hline Group of Students & $\mathrm{N}$ & Posttested MAAS & Pretested MAAS & MAAS Gain \\
\hline Control & 340 & 68 & 49 & 19 \\
\hline Experimental & 300 & 89 & 47 & 42 \\
\hline
\end{tabular}

Table1 shows that students in control group have pretest MAAS $=49$ and posttest MAAS $=68$ with MAAS gain $=19$; students in experimental group have pretest MAAS $=47$ and posttest MAAS $=89$ with MAAS gain $=42$. The MAAS gain of 19 obtained by students in control group tested with CAT 2, Unguided Multiple Choice Objective Questions Test, is less than the MAAS gain of 42 obtained by students in experimental group tested with CAT 3, Guided Multiple Choice Objective Questions Test, by 23. The implication is that the Guided Multiple Choice Objective Questions Test improved the Mean Academic Achievement Scores of the students, to a very great extent, more than the Unguided Multiple Choice Objective Questions Test.

\subsection{Research Question 2}

To what extent has Guided Multiple Choice Objective Questions Test improved the Mean Academic Achievement Scores of Female Students in Senior School Mathematics? 


\subsection{Answer To Research Question 2}

The extent which the Guided Multiple Choice Objective Questions Test improved the Mean Academic Achievement Scores of Female students in Senior School Mathematics is as shown in table 2.

Table 2: Pretest-Posttest Mean Academic Achievement Scores (MAAS) of SS2 Female Students in Senior School Mathematics

\begin{tabular}{|l|c|c|c|c|}
\hline Group Of Female Students & N & Posttested MAAS & Pretested MAAS & MAAS Gain \\
\hline Control & 113 & 63 & 34 & 29 \\
\hline Experimental & 176 & 81 & 37 & 44 \\
\hline
\end{tabular}

Table 2 shows that female students in control group have pretest MAAS $=34$ and Posttest MAAS $=63$ with MAAS gain $=$ 29; the Female students in the experimental group have pretest MAAS $=37$ and posttest MAAS $=81$ with MAAS gain $=$ 44. This shows that the Guided Multiple Choice Objective Questions Test, CAT 3, improved the Mean Academic Achievement Scores of Female Students in Senior School Mathematics, to a very great extent, more than the Unguided type, CAT 2.

\subsection{Research question 3}

To what extent has Guided Multiple Choice Objective Questions Test improved the Mean Academic Achievement Scores of Male Students in Senior School Mathematics?

\subsection{Answer to Research Question 3}

The extent which Guided Multiple Choice Objective Questions Test improved Mean Academic Achievement Scores of Male students in Senior School Mathematics is as shown in table 3

Table 3: Pretest-Posttest Mean Academic Achievement Scores (MAAS) of SS2 Male Student in Senior School Mathematics

\begin{tabular}{|l|c|c|c|c|}
\hline Group Of Male Students & N & Posttest MAAS & Pretest MAAS & MAAS Gain \\
\hline Control & 227 & 58 & 21 & 37 \\
\hline Experimental & 124 & 85 & 24 & 61 \\
\hline
\end{tabular}

From table 3, it is shown that Male students exposed to Guided Multiple Choice Objective Questions Test, CAT 3, scored MAAS=85 in the Posttest, while their counterparts, in the control group, exposed to Unguided Multiple Choice Objective Questions Test, CAT 2, scored MAAS=58 in the posttest; the Male students in the experimental group have a higher MAAS gain $=61$ than the Male students in the control group with MAAS gain $=37$. The difference in MAAS gain is 27 in favor of the experimental group. This shows that the Guided Multiple Choice Objective Questions Test, CAT 3, has much greater impact on Male students in terms of improving their Mean Academic Achievement Scores than the Unguided Multiple Choice Objective Questions Test, CAT 2.

\subsection{Research Question 4}

How has Guided Multiple Choice Objective Questions Test Mean Academic Achievement Scores of SS2 Female students vis-à-vis their SS2 male counterparts in Senior School Mathematics?

\subsection{Answer to Research Question 4}

The extent of enhancement of academic achievement of SS2 Female students vis-à-vis their male counterparts in Senior School Mathematics when exposed to Guided Multiple Choice Objective Questions Test is as shown in table 4. 
Table 4: Pretest-Posttest Mean Academic Achievement (MAA) Analysis of SS2 Female and Male Students in Senior School Mathematics

\begin{tabular}{|l|c|c|c|c|}
\hline Sex Of SS2 Students & N & Post tested MAA & Pretested MAA & MAA Gain \\
\hline Female & 176 & 89 & 47 & 42 \\
\hline Male & 124 & 91 & 48 & 43 \\
\hline
\end{tabular}

Data in table 4 indicate that both SS2 Female and Male students have appreciable MAA gain. The Female students have MAA gain $=42$, while the Male students have MAA gain $=43$. The higher posttested MAAs of both Female and Male students over their pretested MAAs show that Guided Multiple Choice Objective Questions Test, CAT 3, enhances academic achievement of both Female and Male students in Senior School Mathematics in an unbiased manner. Simply put, gender or sex of students does not affect academic achievement of students tested with guided multiple choice objective questions.

\subsection{Testing of Null Hypotheses}

In order to retain or reject the four null hypotheses posted in this study, they were tested at 0.05 level of significance on a 2-tailed test using Z-test statistic.

$\mathrm{HO}_{1}$ : There is no significant difference between the academic achievement of SS2 students exposed to Guided and Unguided Multiple Choice Objective Questions Tests in Senior School Mathematics.

MAA of SS2 students in the control and experimental groups were subjected to z-test analysis as shown in table 5. This was to ascertain whether the difference in MAA was significant or not.

Table 5: Z-test Analysis of MAA of SS2 Students Exposed to Guided and Unguided Multiple Choice Objective Questions Tests in Senior School Mathematics

\begin{tabular}{|l|c|c|c|c|c|c|c|}
\hline Group of SS2 Students & $\mathbf{N}$ & MAA & $\mathbf{S D}$ & $\mathbf{d f}$ & $\mathbf{Z}_{\text {cal }}$ & $\mathbf{Z}_{\text {crit }}$ & $\mathbf{P}$ \\
\hline Control & 340 & 68 & 10 & \multirow{2}{*}{638} & 27.96 & 1.96 & $<0.05$ \\
\hline Experimental & 300 & 89 & 9 & & & & \\
\hline
\end{tabular}

Data in table 5 show that $Z_{\text {cal }}=27.96>Z_{\text {crit }}=1.96$. Therefore, $\mathrm{HO}_{1}$ is rejected. This implies that the difference in MAA is significant in favor of the students in the experimental group, exposed to Guided Multiple Choice Objective Questions Test.

$\mathrm{HO}_{2}$ : There is no significant difference between the academic achievements of SS2 female students exposed to Guided and the other group of female students exposed to Unguided Multiple Choice Objective Questions Tests in Senior School Mathematics.

MAA of SS2 female students in the control and experimental groups were subjected to z-test analysis as shown in table 6, in order, to know whether the difference in MAA was significant or not.

Table 6: Z-test Analysis of MAA of SS2 Female Students Exposed to Guided and Unguided Multiple Choice Objective Questions Tests in Senior School Mathematics

\begin{tabular}{|l|c|c|c|c|c|c|c|}
\hline SS2 FEMALE STUDENTS & $\mathbf{N}$ & MAA & SD & DF & $\mathbf{Z}_{\text {cal }}$ & $\mathbf{Z}_{\text {crit }}$ & $\mathbf{P}$ \\
\cline { 1 - 6 } Control & 113 & 63 & 9.0 & \multirow{2}{*}{287} & \multirow{2}{*}{16.88} & 1.96 & $<0.05$ \\
\hline Experimental & 176 & 81 & 8.6 & & & \\
\hline
\end{tabular}

From table 6, it is evident that $Z_{\text {cal }}=16.88>Z_{\text {crit }}=1.96$. Consequently, $\mathrm{HO}_{2}$ is rejected. The implications are that the difference in MAA is significant and in favor of the Female students in the experimental group, exposed to Guided Multiple Choice Objective questions test.

$\mathrm{HO}_{3}$ : There is no significant difference between the academic achievement of SS2 Male students exposed to Guided and Unguided Multiple Choice Objective Questions Tests in Senior School Mathematics.

MAA of SS2 Male students in the control and experimental groups were subjected to z-test analysis as shown in table 7 , in order, to find out if the difference in MAA was significant or not. 
Table 7: Z-test Analysis of MAA of SS2 Male Students Exposed to Guided and Unguided Multiple Choice Objective Questions Tests in Senior School Mathematics

\begin{tabular}{|l|c|c|c|c|c|c|c|}
\hline SS2 Male Students & $\mathbf{N}$ & MAA & SD & Df & $\mathbf{Z}_{\text {cal }}$ & $\mathbf{Z}_{\text {crit }}$ & $\mathbf{P}$ \\
\hline Control & 227 & 58 & 7.6 & 349 & 33.79 & 1.96 & $<0.05$ \\
\hline Experimental & 124 & 85 & 6.9 & & 3 & & \\
\hline
\end{tabular}

The Z-test analysis in table 7 shows that $Z_{\text {cal }}=33.79>Z_{\text {crit }}=1.96$, indicating a significant difference between the MAAs scored by students in the control and experimental groups in favor of the students in the experimental group, exposed to Guided Multiple Choice Objective Questions Test. The implication is that $\mathrm{HO}_{3}$ is rejected.

$\mathrm{HO}_{4}$ : There is no significant difference in academic achievement between SS2 Female and Male students exposed to Guided Multiple Choice Objective Questions Tests in Senior School Mathematics.

The MAAs of SS2 Female and Male students exposed to Guided Multiple Choice Objective Questions Test were subjected to z- test analysis, as shown in table 8, to find out if the difference in MAA was significant or not.

Table 8: Z-test Analysis of MAA of SS2 Female and Male Students in Senior School Mathematics.

\begin{tabular}{|l|c|c|c|c|c|c|c|}
\hline Sex of SS 2 students & N & MAA & SD & Df & Zcal & Zcrit & P \\
\hline Female & 176 & 89 & 9.3 & \multirow{2}{*}{298} & \multirow{2}{*}{1.77} & \multirow{2}{*}{1.96} & $<0.05$ \\
\hline Male & 124 & 91 & 9.9 & & & \\
\hline
\end{tabular}

Table 8 shows z-test analysis of MAA of the SS2 Female and Male students, where $z_{\text {cal }}=1.77<z_{\text {crit }}=1.96$, indicating no significant difference in their MAA score. $\mathrm{HO}_{4}$ is hereby retained. The implication is that the Guided Multiple Choice Objective Questions Test favors both the Female and Male students in terms of enhancement in academic achievement in Senior School Mathematics.

\section{Discussion of the Findings}

The purpose of this study was to find out the Comparative Effects of Guided and Unguided Multiple Choice Objective Questions Tests (GMCOQT and UMCOQT) on academic achievement of SS2 students in Senior School Mathematics by Gender in Delta State Capital Territory of Nigeria. The discussion was done in order of research questions and hypotheses guiding this study.

The findings shown in tables I, 2 and 3 indicate higher posttested MAA of SS2 students exposed to Guided Multiple Choice Objective Questions Test than their SS2 counterparts exposed to Unguided Multiple Choice Objective Questions Test. This was found to be significant when subjected to z-test, as shown in tables 5, 6 and 7. This agrees with the finding of Igbojinwaekwu (2012) who affirms that Senior School Students exposed to Guided Multiple Objective Questions Test had higher performance than those exposed to Unguided Multiple Choice Objective Questions Test in Senior School Oral English Examination. This finding, also, agrees with Ndu Okeke and Igbojinwaekwu (2005) who asserts that Unguided Multiple Choice Objective Questions Test breeds regurgitation of facts, memorization, low academic achievement and against application of facts, while Guided Multiple Choice Objective Questions Test encourages fast recall of facts, application of knowledge and high academic achievement of students in Senior School Examinations. This might be due to the fact that the Guided Questions led the students to the correct answers, without many difficulties, unlike the Unguided type.

An interesting finding in this study is that, irrespective of sex of the students, Guided Multiple Choice Objective Questions Test enhanced, to a very appreciable extend, the academic achievement of SS2 Students used in this study, although Male SS2 students have higher MAA than their Female counterparts. However, the difference between MAAs of Male and Female SS2 students was not significant, statistically. This agrees with findings of Onwukwe and Onwukwe (2011) and Joseph (2002) that students who spend more guided time on task, on individual basis, have higher academic achievement than those who spend more unguided time on task. This might be because the Guided Multiple Choice Objective Questions Test helped the students to remove irrelevances associated with the questions asked. The finding of no significant difference in performance by gender and higher academic achievement of students in Senior School Mathematics as found in table 8, irrespective of sex, agree with the findings of Ndu, Okeke and Igbojinwaekwu (2005) who posit that when a good test instrument, devoid of ambiguities, is used for examination test, both boys and girls will have very high academic achievement in science subjects and mathematics. This may be because a good test 
instrument guides the students to the subject matter, thereby reducing the problems associated with memorization and regurgitation of facts.

\section{Summary of the findings}

This study investigated the Comparative Effects of Guided and Unguided Multiple Choice Objective Questions Tests (GMCOQT and UMCOQT) on academic achievement of SS2 students in Senior School Mathematics by gender. The following findings were prominent.

The SS2 students exposed to Guided Multiple Choice Objective Questions Test have higher post tested Mean Academic Achievement in the Senior School Mathematics than the SS2 students exposed to Unguided Multiple Choice Objective Questions Test in all ramifications. Gender did not affect the academic achievement of SS2 students tested with Guided Multiple Choice Objective Questions; both Male and Female SS2 students have very appreciable MAA gain when posttested with GMCOQT. The difference between the posttested MAAs of SS2 Male and Female students in Senior School Mathematics, show no statistical significant difference.

\section{Implications for Practice and Future Research}

One of the findings of this study, worth mentioning, is that SS2 students exposed to Guided Multiple Choice Objective Questions Test have appreciable significant higher mean academic achievement than the SS2 students exposed to Unguided Multiple Choice Objective Questions Test. This implies that teachers worldwide should imbibe the culture of using Guided Multiple Choice Objective Questions Test in continuous assessment and terminal examinations, in order, to drastically reduce the high rate of failure. They should, as a matter of urgency, discard Unguided Multiple Choice Objective Questions Test, which is a miss-match to the present day Information and Communications Technology (ICT).

Another worthy finding in this study is the non-significant very high mean academic achievement of SS2 students in Senior School Mathematics by gender. The implication is that both male and female students were favored or advantaged when exposed to Guided Multiple Choice Objective Questions Test in Senior School Mathematics Examination. Using Guided Multiple Choice Objective Questions Test to examine students in the science subjects and mathematics at the time many scholars (Akpan, 1987; Ndu, Okeke and Igbojinwaekwu, 2005; Maduabum and Odili, 2006; Jona-Eteli, 1999; Ogidi, Chikwe and Nwachukwu, 2011) are calling for educationists to think of ways to encourage more girls into science and mathematics oriented careers is a welcome development. Lowering the cut-off point of female students in some national examinations is to make them inferior to their male counterparts.

This research can be replicated in other subjects and in other countries, in order, to find out whether the findings in this study are applicable to other subjects and countries. Besides, this study can be carried out in Junior Secondary Schools in Nigeria to ascertain if the findings in this study in Senior Secondary Schools are applicable to Junior Secondary Schools.

\section{Recommendations}

The researcher, therefore, has the following recommendations:

That teachers should make use of guided multiple choice objective questions test when assessing students, be given adequate training on generating guided multiple choice objective questions and examining bodies should supply all the formulae needed in Mathematics Examinations to students, in order, to support the use of guided multiple choice objective questions test and applications of knowledge, rather than memorization and regurgitation of facts.

\section{Conclusion}

Guided Multiple Choice Objective Questions Test enhanced, to a very great extent, a very high and significant academic achievement of SS2 Students than the Unguided type. There was no-significant difference between the high mean academic achievement of Male and Female SS2 Students exposed to Guided Multiple Choice Objective Questions Test.

\section{Acknowledgements}

The researcher gives thanks to the principals of secondary schools, in DSCT, used in this study. Also, thanks are due to 
teachers and students used in this study during teaching-learning process. The authority of Niger Delta University deserves thanks for catalyzing this research. The researcher is highly indebted to Professor John Cecil Buseri of Niger Delta University, Faculty of Education, Department of Teacher Education, Wilberforce Island, Bayelsa State, Nigeria for his mentoring.

\section{References}

Akinsola, M.K. and Popoola, A.A. (2004). A comparative study of the effectiveness of two strategies of solving mathematics problems on the academic achievement of secondary school student, Abacus: Journal of the Mathematical Association of Nigeria (JMAN), 29(1), 11-18.

Akpan, E.U.U. (1987). Winning more students for science and technology. 28 $8^{\text {th }}$ Annual Conference Proceedings of Science Teachers Association of Nigeria.

Akuezuilo, E.O. and Chinweoke, F.U. (2009). Effectiveness of prior knowledge of behavioural objectives and study questions of female students mathematics achievement. Unizik Journal of STM Education, 1(1), 1-7

Ali, A. (2010). Improving Educational Standard In Nigeria. In T.O Oyetunde,S.Y. Aliyu M.P. Haggai and M.J Musa (Eds). Improving Educational Standard In Nigeria Perspective ,Challenges And Strategy . Zaria, Nigeria Ahmadu Bello University Press.

Chinweoke, F.U. (2008). Use of advance organizers as an instructional strategy for teaching of undefined fractions. Journal of Science teachers association of Nigeria (JSTAM), 11 (1).12-20.

Egbule, J.F. (2002).Fundamentals of test, measurement and evaluation. Owerri Nigeria, Whyte and Whyte Publishers.

Egbule, J.F and Okobia, D.O (2006).Research methods in education for colleges and universities. Onitsha, Nigeria, Kmensuo Educational Publishers.

Eguavon, O.J. (2002). Mathematics the heartbeat of information technology: Implication for secondary Education. Abacus: JMAN, 27 (1), $10-12$.

F.R.N. (2013). National policy on education. Lagos, NERDC Press.

Harbor-Peters V.F.A. (2001). Unmasking some aversive aspect of schools mathematics and strategies for averting them Inaugural Lecture at university of Nigerian Nsukka, Nigeria.

Igbojinwaekwu, P.C. and Nneji, N.L. (2012). Restructured mathematics questions and academic achievement of students in senior school mathematics. African Indices, British University in Egypt (BUE), Etsharonk City, Cairo, 4 (1), 14-23.

Igbojinwaekwu, P.C. (2011). Effectiveness of the use of graphed board on students' academic achievement in senior school mathematics. Journal of prestine, Ahmadu Bello University, Zaria, Nigeria, 3 (1), 1-7.

Igbojinwaekwu, P.C. (2013). Impact of Videotaped Instruction on Learning of Mathematics at Senior School Level. Journal of Prestine, Ahmadu Bello University, Zaria, Nigeria, 7 (1), 1-9.

Igbojinwaekwu, P.C. (2002). Gender differences in enrolment pattern and academic achievement of students in senior school science and mathematics in Nigeria. PhD Thesis, Department of Science Education, Unizik, Awka, Nigeria.

Igbojinwaekwu, P.C. (2009). Academic achievements of extroverted and introverted students in senior school mathematics. Unizik Journal of STM Education, 1(1), 96 - 102.

Imoko, B.I. and Agwagah, U.N.V. (2006). Improving students interest in mathematics through the concept mapping technique. a focus on gender. Journal of Research in Curriculum and Teaching, 1 (1), 30-38.

Jonah-Eteli, W.A. (1999). Measurement and evaluation in education, with revision exercises. Owerri, Nigeria. Springfield Publishers.

Joseph, P.M. (2002). Concentric plan of teaching practical chemistry from first to final year of senior secondary school, in: B. Ezeliora (Eds). Proceeding of annual national chemistry workshop of science teachers association of Nigeria.

Maduabum, M.A. (2004). Fundamentals of educational research. Owerri, Nigeria, Versatile Printers.

Maduabum, M.A. and Odili, G.A. (2006). Analysis of Students' performance in General Mathematics at the Senior School Certificate Level in Nigeria from 1991-2002. Journal of Research in Curriculum and Teaching , 1(1), 64-68.

Mafiane, C.F. (2006). Strengthening the internal quality assurance mechanism in the higher educational institution. Paper Presented at Training Workshop for Directors of Academic Planning in Nigeria Tertiary Institution at Abuja 18 $8^{\text {th }}$ 21 $1^{\text {st }}$ July, 2006.

Musheu, B.J. and Tijani, O.A. (20011). Quality teacher education and national productivity issues and challenges. The Nigerian academic forum: A multidisciplinary Journal. 21(1) 50-57

Ndu, F.O.C., Okeke, S.O.C. and Igbojinwaekwu, P.C. (2005). Competitive learning environment and academic achievement of girls in Senior School Science and Mathematics. IJOFAWEN, 1 (3), 154 - 160.

Njoku, Z.C. (2007). Comparison of student's achievement in the three categories of questions in Senior School Certificate Examination Practical Chemistry Journal of Science Teachers Association of Nigeria. 42 (1 \& 2), 67-72.

Oghenevwede, O. E. (2012). Enhancing the retention level of biology students through the guided discovery instructional method. Nigerian Journal of Curriculum and Instruction, 19(1), 7-12.

Ogidi, R.C., Chikwe, C.K and Nwachukwu, K. (2011). Teachers' competency for effective implementation of school based assessment in Rivers State. Journal of Issues in Professional Teacher Education (JIPTE), 2 (2), 67-82.

Okigbo, E.C and Okeke, M.C (2011). Availability and use of improvised visual aids for teaching solid geometry in secondary schools. UNIZIK Journal Of Science Technology And Mathematics (STM) Education, 1(2), 55-60

Onwukwe, E.O. and Onwukwe, C.M. (2011). The use flow chart as individualized instruction in importing titrimetric analytical skills to 
chemistry students. UNIZIK Journal of STM Education, 1 (2), 118-129.

Opara, J.A. (2004). Refocusing research in science, technology and mathematics education in Nigeria issues, challenges and the way out. $45^{\text {th }}$ Annual Conference Proceeding of JSTAN.

Soyemi, B.O. (2002). Student dictionary of mathematics. Nigeria, Educare Foundation.

Tsue, E.A and Anyor, J.W. (2006). Relationship between students' achievement in secondary school mathematics and science subjects. Journal of Research in Curriculum and Teaching, 1(1), 48-54.

UNESCO (2000). Difficulties faced by girls in the study of science, mathematics and technology. Findings of Female in Education in Mathematics and Science in Africa (FEMSA). Project connect, XXIII (3/4), 1-3.

WAEC (2012). Chief examiner's report. Lagos, Nigeria, West African Examinations Council.

WAEC (2013). Chief examiner's report. Lagos, Nigeria, West African Examinations Council.

WAEC (2014) Chief examiner's report. Lagos, Nigeria, West African Examinations Council.

\section{APPENDIX 1: COMPARATIVE ACHIEVEMENT TEST}

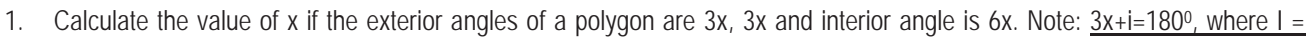
interior angle.

A) $18^{\circ}$ B) $30^{\circ}$ C) $40^{\circ}$ D) $60^{\circ} \mathrm{E}$ ) it cannot be determined

2. The angles of a pentagon are $x^{0}, 2 x^{0},(x+60)^{0},(x+10)^{0}$ and $(x-10)^{0}$.

3. Find the value of $x$. Note: $(2 n-4) 90=$ sum of interior angles of a polygon, $n=$ number of sides of the polygon. A) 40 B) 60 C) 75 D) 80 E) 90

4. In a given regular polygon, the ratio of the exterior angle to the interior angle is 1:3.

How many sides have the polygon? Note: $\mathrm{e}+\mathrm{i}=180^{\circ}$, sum of exterior angles of a polygon $=360^{\circ}$ and $360 / \mathrm{e}=$ number of sides of a polygon, where $\mathrm{e}=$ exterior angle and $i=$ interior angle of a polygon

A) 4 B) 5 C) 6 D) 8 E) 12

5. The angles $2 x, 3 x, 3 x, 2 x$ and $5 x$ are exterior angles of a polygon. Find $x$. Note: sum of exterior angles of a polygon $=360^{\circ}$ A) $15^{\circ}$ B) $\left.24^{\circ} \mathrm{C}\right) 30^{\circ}$ D) $36^{\circ}$ E) $48^{\circ}$

6. A regular polygon has each of its exterior angles as $1^{\circ}$. How many sides has the polygon? Note: Sum of exterior angles of a polygon $=360^{\circ}$ and $360 / e=$ number of sides of a polygon, where $e=e x t e r i o r$ angle of a polygon

A) 10 B) 11 C) 12 D) 20 E) 24

7. The sum of the interior angles of a regular polygon is 30 right angles. How many sides have the polygon? Note: right angle $=90^{\circ}$ and $(2 n-4) 90=$ sum of interior angles of a polygon, $n=$ number of sides of the polygon.

A) 34 B) 30 C) 26 D) 17 E) 15

8. The sum of the angles of a regular polygon is $2520^{\circ}$. How many sides does the polygon have? $(2 n-4) 90=$ sum of interior angles of a polygon, $n=$ number of sides of the polygon.

A) 20 B) 18 C) 17 D) 16 E) 15

9. Which of the following angles is an exterior angle of a regular polygon? Note: Sum of exterior angles of a polygon $=360^{\circ}$ and $360 / e=$ whole number, where $e=$ an exterior angle of a polygon.

A) $95^{\circ}$ B) $85^{\circ}$ C) $78^{\circ}$ D) $75^{\circ}$ E) $72^{\circ}$

10. How many sides has a polygon if the sum of its interior angle is $1440^{\circ}$ ?

Note: $(2 n-4) 90=1440^{\circ}, n=$ number of sides

A) 6 B) 7 C) 8 D) 9 E) 10

11. Each interior angle of a regular nonagon (nine sided polygon) is equal to

A) $160^{\circ}$ B) $\left.\left.\left.144^{\circ} \mathrm{C}\right) 140^{\circ} \mathrm{D}\right) 132^{\circ} \mathrm{E}\right) 36^{\circ}$

12. $4 x, 3 x, 2 x$ and $5 x$ are interior angles of a polygon. Calculate $x$ correct to nearest degree. Note: Sum of exterior angles of a polygon $=360^{\circ}$

A) $15^{\circ}$ B) $26^{\circ}$ C) $26^{\circ}$ D) $36^{\circ}$ E) $72^{\circ}$

13. The interior angles of a pentagon( 5 -sided figure) are $126^{0}, 114^{0}, y, 92^{\circ}$ and $83^{\circ}$. Find the value of $y$. Note: $(2 n-4) 90=$ sum of interior angles of a polygon, $n=$ number of sides of the polygon

A) $85^{\circ}$ B) $95^{\circ}$ C) $105^{\circ}$ D) $115^{\circ}$ E) $125^{\circ}$

14. The interior angle of a regular polygon is twice the exterior angle. How many sides has the polygon? Note: $\mathrm{e}+\mathrm{i}=180^{\circ}$, sum of exterior angles of a polygon $=360^{\circ}$ where $e=e x t e r i o r$ angle and i=interior angle of a polygon.

A) 5 B) 6 C) 8 D) 9

15. Each side of a regular convex polygon subtends an angle of $30^{\circ}$ at its centre. Calculate each interior angle. Note: angle at a point $=360^{\circ}$

A) $75^{\circ}$ B) $150^{\circ}$ C) $160^{\circ}$ D) $168^{\circ}$ E) $50^{\circ}$

16. If the interior angles of a hexagon (6-sided figure) are $1070,2 x^{0}, 150^{0}, 95^{\circ} .(2 x-15)^{0}$ and $123^{\circ}$, Find $x$.

A) $57.5^{\circ}$ B) $65^{\circ}$ C) $106^{\circ}$ D) $120^{\circ}$ E) $150^{\circ}$

17. An interior angle of a regular polygon is 5 times each exterior angle. how many sides has the polygon? Note: e+i=180 where $e=e x t e r i o r$ angle and $i=$ interior angle of a polygon.

A) 15 B) 12 C) 9 D) 6 
18. Each exterior angle of a polygon is $30^{\circ}$. Calculate the sum of the interior angles. Note: e+i=1800and (2n-4)90=sum of interior angles of a polygon, $n=$ number of sides of the polygon and $e=e x t e r i o r$ angle and $i=i n t e r i o r$ angle of a polygon. A) $540^{\circ}$ B) $720^{\circ}$ C) $1080^{\circ}$ D) $\left.1800^{\circ} \mathrm{E}\right) 500^{\circ}$

19. Two interior angles of a pentagon (5-sided figure) are in ratio $2: 3$ the others are $60^{\circ}$ each. Calculate the smaller of the two angles. Note: $(2 n-4) 90=$ sum of interior angles of a polygon, $n=$ number of sides of the polygon.

A) $72^{\circ}$ B) $100^{\circ}$ C) $120^{\circ}$ D) $\left.144^{\circ} \mathrm{E}\right) 670^{\circ}$

20. Which of the following is/are not the interior angle(s) of a regular polygon?

Note: $\mathrm{e}+\mathrm{i}=180^{\circ}$ where e =exterior, i=interior angle of a polygon and $360 / \mathrm{e}=$ whole number.

| $108^{\circ}$ || $116^{\circ}$ ||| $120^{\circ}$

A) I only B) II only C) III only D) I and III only E) I, II and III.

UNDERLINED STATEMENT AS GUIDE IN EACH QUESTION 